Article

\title{
Arenesulfonic Acid-Functionalized Bentonite as Catalyst in Glycerol Esterification with Acetic Acid
}

\author{
Maryam Tangestanifard and Hassan S. Ghaziaskar * \\ Department of Chemistry, Isfahan University of Technology, Isfahan 84156-83111, Iran; \\ m.tangestanifard@gmail.com \\ * Corresponding: ghazi@cc.iut.ac.ir; Tel.: +98-31-33913260; Fax: +98-31-33912350
}

Received: 13 May 2017; Accepted: 3 July 2017; Published: 14 July 2017

\begin{abstract}
The present study is focused on the synthesis of arenesulfonic acid-functionalized bentonite as a catalyst to produce monoacetin, diacetin, and triacetin from glycerol and acetic acid using toluene as solvent and a water removing agent. The best conditions for the present reaction with acetic acid were an acetic acid:glycerol:toluene molar ratio of 7:1:1.4, $100{ }^{\circ} \mathrm{C}$, and $0.074 \mathrm{wt} \%$ of catalyst (based on the total weight of glycerol). Under the reaction conditions, $96 \%$ glycerol conversion was achieved within $0.5 \mathrm{~h}$ from the start of the reaction. The maximum selectivity of $66 \%$ and $74 \%$ were achieved for diacetin and triacetin after 0.5 and $3 \mathrm{~h}$ of reaction, respectively, without formation of any byproduct. The arenesulfonic acid-functionalized bentonite was characterized by X-ray diffraction, thermogravimetric analysis, Fourier transform infrared spectroscopy, $\mathrm{N}_{2}$ adsorption/desorption experiments (Brunauer, Emmett and Teller, BET, method), field emission scanning electron microscopy, and the surface acidity was determined by back titration. Without significant treatment, the catalyst was reusable for 5 consecutive runs.
\end{abstract}

Keywords: functionalized bentonite; esterification; acetins; glycerol; glycerol conversion

\section{Introduction}

Biodiesel is made from renewable stock including vegetable oils and animal fats via a transesterification reaction. Glycerol is produced in huge quantities from the process of biodiesel production. Hence, much effort is made to convert glycerol into useful products by a variety of catalytic reactions [1-3]. Glycerol can be utilized for the synthesis of biodiesel additives as well as industrial solvents such as propylene glycols, glycerol ethers, esters, glycerol carbonate, glyceric acids, and other products. Glycerol as oxygenated additive and cannot be added directly to fuel because it can be decomposed and polymerized at high temperatures in the engine. Therefore, glycerol is converted to the compounds that can be used as fuel additives [4]. For example, acetines, especially diacetin (DA) and triacetin (TA), are used as important additives to improve the cold properties and decrease the viscosity of biodiesel.

Acetines can be synthesized by reaction between glycerol and acetic acid over homogeneous mineral acids, such as $\mathrm{H}_{2} \mathrm{SO}_{4}, \mathrm{HCl}$, and $\mathrm{H}_{3} \mathrm{PO}_{4}$ [5], and heterogeneous solid acids including sulfonic acid groups supported mesoporous silica [6], niobic acid, Starbon acid, niobic acid supported heteropolytungstate, dodecatungstophosphoric acid immobilized on to a silica matrix, supported ionic liquids, TPA supported on Cs-containing zirconia, Amberlysts [7,8], $\mathrm{SO}_{4}{ }^{2-} / \gamma-\mathrm{Al}_{2} \mathrm{O}_{3}$ and $\mathrm{Cu}-\mathrm{Ni} / \gamma-\mathrm{Al}_{2} \mathrm{O}_{3}$ catalyst [5], zeolites, Lewis acid $\mathrm{SnCl}_{2}$, heteropolyacids loaded materials, acid-treated montmorillonite clay, and some other catalysts [8-11]. These heterogeneous catalysts can prevent reactor corrosion, difficult catalyst separation, and extra neutralization of the homogeneous catalyst and production of waste and side products. However, the solid acid catalysts have some disadvantages such as the small amount of acidic sites, low thermal stability, quick loss of catalytic activity, and 
pore-size restriction (as zeolites with small pore size provide poor selectivity to DA and TA) $[5,12]$. Moreover, water could deactivate the acidic sites due to competition with the reactants or cause leaching of the hydrophilic support of the solid catalysts and inhibit the esterification reaction which results in low selectivity for the favored DA and TA $[9,12]$. Thus, a water-tolerant solid acid catalyst or water removal substances are necessary for the esterification of glycerol $[4,8]$. However, lower usability, poor hydrothermal stability, and low selectivity to TA has been presented due to the catalyst preparation methods. It was described that catalysts provided by a grafting method via reaction of the functional groups of the support with the metal precursor can prevent migration, agglomeration, and sintering throughout the following thermal treatments. Regarding the disadvantages, catalysts prepared by wet impregnation method, progressing through the chemi- or physisorption of metal groups onto the support surface, suffer from remarkable leaching and present low selectivity to TA. For solving these problems, mesoporous silicate and aluminosilicate samples can be considered for glycerol esterification with acetic acid. Despite the porosity and large pore diameter of these catalysts, some problems such as the low degree of effective acidic sites over these mesoporous solids exist. However, these drawbacks can be improved by acidifying and functionalizing mesoporous solids with sulfonic groups [1,9].

The modification of bentonite clays was studied by pillaring or intercalation of complexes, anions, and organic compounds between layers of clay minerals. These modifying processes caused different properties and reactivities that increased the requests for this group of clay minerals as catalysts [13].

In this work, a reusable, environmentally friendly, and inexpensive catalyst with good catalytic performance and thermal stability was produced using bentonite as a support, grafted by benzylsulfonic acid groups. The catalyst performance was then examined for the esterification of glycerol with acetic acid. The reaction was studied under reaction parameters optimized in our previous work [14] and a Dean-Stark apparatus was used to separate water from the products.

\section{Results and Discussion}

Heterogeneous catalysts have shown good activity for glycerol esterification but big challenges such as low reusability, poor thermal stability, and selectivity to TA still exist for the proper design of an appropriate solid catalyst in esterification reactions. In fact, the water produced in the esterification reaction may lead to deactivation of acidic sites. One of the methods for preparing stable catalyst involves grafting of a modifying agent into surface of inorganic supports and continuous removal of water from the reaction medium. Therefore, we decided to modify natural bentonite (BEN) as a support for manufacturing arenesulfonic acid-functionalized catalyst using the following procedure (Scheme 1). Raw bentonite was activated by $\mathrm{HCl}$ and benzyl alcohol, respectively, to give arylbentonite (Ar-BEN) with covalent bonds between the hydroxyl groups of the bentonite layer and benzyl alcohol molecules. The benzyl groups then were reacted with $\mathrm{ClSO}_{3} \mathrm{H}$ to produce arenesulfonic acid bentonite (AS-BEN) as catalyst.

Acid activation with $0.1 \mathrm{M} \mathrm{HCl}$ was performed to increase the number of hydroxyl sites on the clay mineral surfaces by formation of structural imperfections in the tetrahedral sheet and by substituting interlayer cations $\left(\mathrm{Na}^{+}, \mathrm{K}^{+}\right.$and $\mathrm{Ca}^{2+}$ ) with hydronium ions without significant leaching of $\mathrm{Al}$ from the bentonite framework and without the loss of the layer pattern [15].

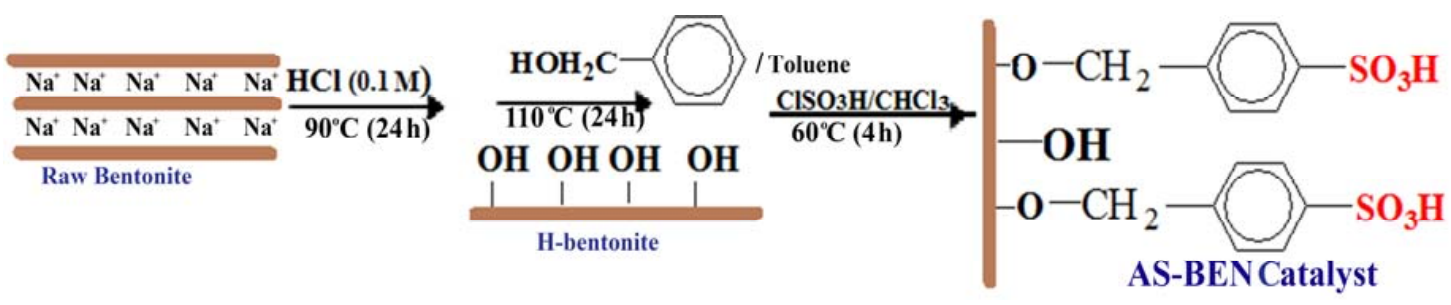

Scheme 1. Synthesis of arenesulfonic acid-functionalized bentonite as catalyst. 
X-ray diffraction (XRD) patterns of acidified bentonite (H-BEN) and AS-BEN are presented as evidence for the demonstration of modified clays. According to the XRD patterns (Figure 1), after grafting of arylsulfonic acid groups to $\mathrm{H}-\mathrm{BEN}$, the characteristic peaks corresponding to montmorillonite at $2 \theta=6.8^{\circ}\left(\mathrm{d}_{001}=1.293 \mathrm{~nm}\right)$ shift to a lower diffraction angle $\left(2 \theta=6.4^{\circ}, \mathrm{d}_{001}=1.381 \mathrm{~nm}\right)[15,16]$. This shift towards a lower angle confirms the intercalation and grafting of arylsulfonic acid groups in the internal and external surfaces of H-BEN [16].

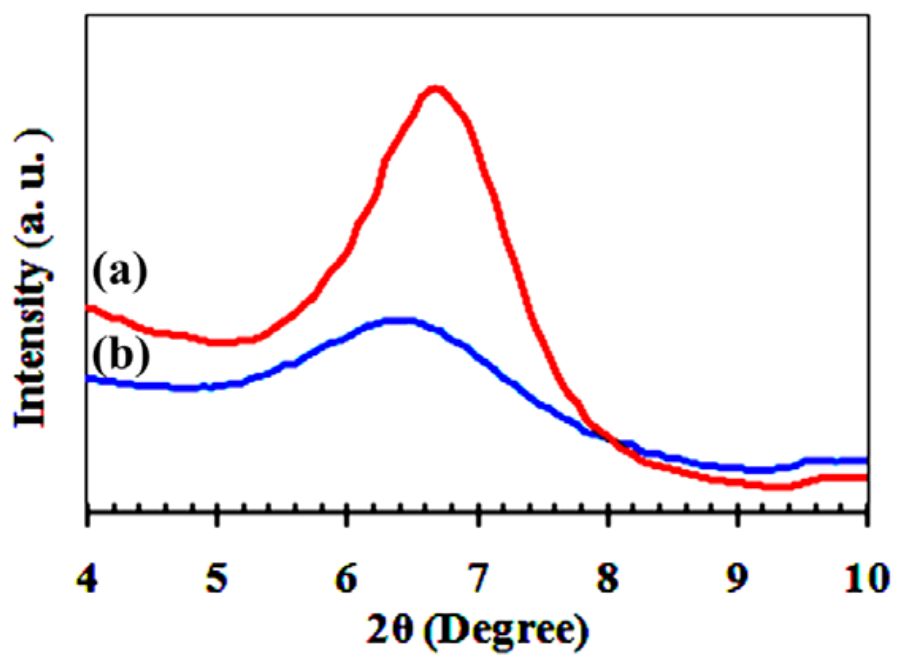

Figure 1. X-ray diffraction patterns of (a) acidified bentonite and (b) arenesulfonic acid bentonite.

Field emission scanning electron microscopy (FE-SEM) was utilized to study the morphology of modified bentonite. Figure 2 shows scanning electron microphotographs of AS-BEN. The characteristic layered structure of clay was retained after functionalization of raw bentonite.
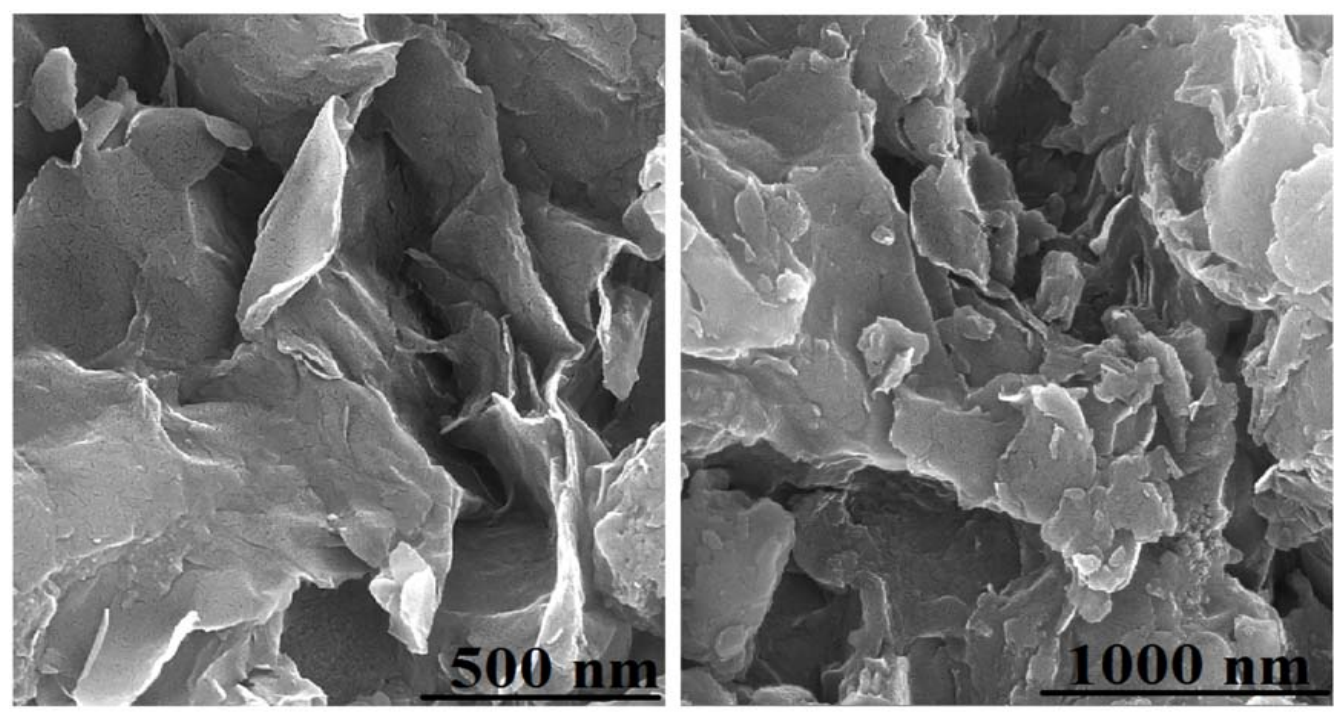

Figure 2. Field emission scanning electron microscopy images of the modified clay (AS-BEN).

All spectra in Figure 3 show vibrational bands at $1089 \mathrm{~cm}^{-1}, 519 \mathrm{~cm}^{-1}$, and $469 \mathrm{~cm}^{-1}$ attributed to the stretching vibrations of $\mathrm{Si}-\mathrm{O}-\mathrm{Si}$ groups and bending vibration of $\mathrm{Si}-\mathrm{O}-\mathrm{Al}$ and $\mathrm{Si}-\mathrm{O}-\mathrm{Si}$, respectively. The bands at $3434 \mathrm{~cm}^{-1}$ and $1635 \mathrm{~cm}^{-1}$ attributed to the stretching vibration and corresponding bending vibration bands from the physically adsorbed water. The relatively strong IR absorption bands around $3629 \mathrm{~cm}^{-1}$ are attributed to the stretching vibration of the $\mathrm{Mg}-\mathrm{OH}, \mathrm{Al}-\mathrm{OH}$, or Fe-OH 
structural hydroxyl groups. Bands at $2850-2935 \mathrm{~cm}^{-1}$ were assigned to the $-\mathrm{C}-\mathrm{H}$ asymmetric and symmetric stretching of the methylene groups and the several bands at $3020-3060 \mathrm{~cm}^{-1}$ were attributed to the stretching vibrations $-\mathrm{C}-\mathrm{H}$ of aromatic groups which confirmed incorporation of the aromatic ring on the surface $[13,16,17]$. In addition, for the $\mathrm{Ph}_{-} \mathrm{SO}_{3} \mathrm{H}$ group, vibrational bands around 1008 , 1036 , and $1178 \mathrm{~cm}^{-1}$ were attributed to the $\mathrm{O}=\mathrm{S}=\mathrm{O}$ symmetric stretching, $\mathrm{C}-\mathrm{S}$ stretching, and $\mathrm{O}=\mathrm{S}=\mathrm{O}$ asymmetric stretching modes of vibration, respectively. However, these bands may overlap the stretching bands of Si-O bonds [18].

Figure 4 shows thermogravimetric curves for H-BEN, Ar-BEN, and AS-BEN catalyst prior to use in the esterification reaction. For unmodified H-BEN, the onset of $11.7 \%$ weight loss starts at $30{ }^{\circ} \mathrm{C}$ and ends at $150{ }^{\circ} \mathrm{C}$, and is caused by desorption of physically adsorbed water from the outer surfaces and between bentonite layers. The second loss-stage $(4.5 \%)$ at $\mathrm{T}>500{ }^{\circ} \mathrm{C}$ can be due to the dehydroxylation of the silicate layers. The Ar-BEN displayed extra weight loss (15\%) at about $200-600{ }^{\circ} \mathrm{C}$ assigned to the loss of bonded benzyl alcohol molecules. The first weight loss between $200-500{ }^{\circ} \mathrm{C}$ was assigned to the benzyl alcohol molecules grafted on the external surface and at the edge of the clay, while the weight loss at about $550^{\circ} \mathrm{C}$ was attributed to the strongly grafted benzyl alcohol molecules in the interlayer regions. In AS-BEN, three stages of decomposition were observed. It is noteworthy that the weight loss of approximately $9 \%$ at $250-350{ }^{\circ} \mathrm{C}$ can be due to the desulfonation of the sulfonic acid groups $[15,16,18]$.

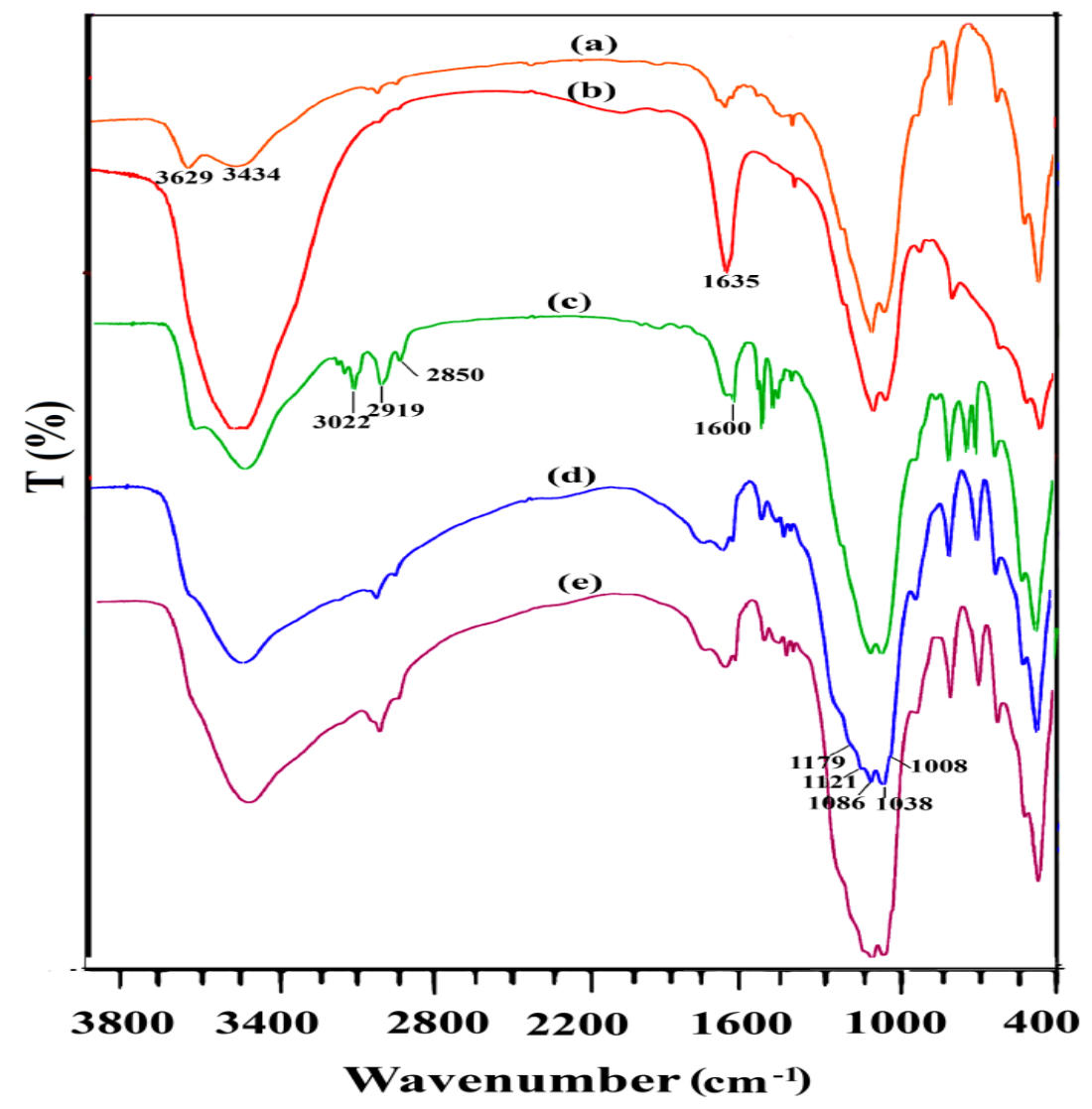

Figure 3. Fourier transform infrared spectra of (a) Raw BEN (b) H-BEN, (c) Ar-BEN, (d) AS-BEN, and (e) spent AS-BEN. 


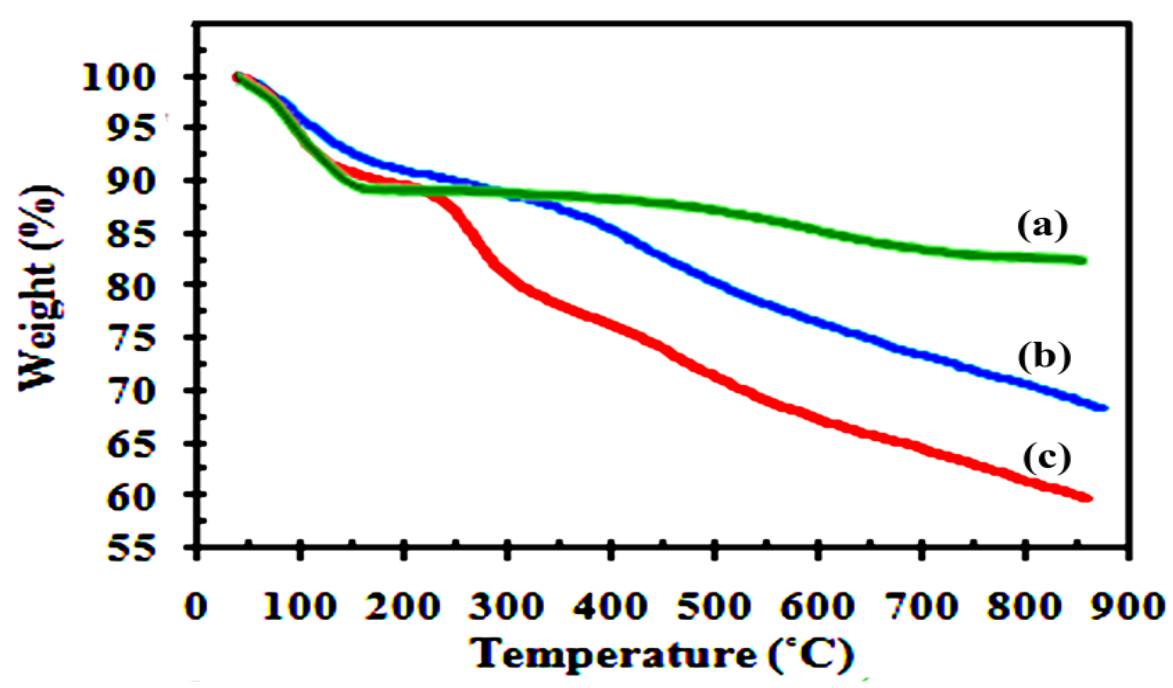

Figure 4. The thermogravimetric analysis curves of the (a) H-BEN, (b) Ar-BEN, and(c) AS-BEN.

The BET surface area, pore volume, and average pore diameter of BEN, H-BEN, and AS-BEN, were summarized in Table 1. The specific surface area was obtained from the linear part of the BET plot. The average pore diameter, pore volume, and pore size distribution were calculated from the $\mathrm{N}_{2}$ adsorption-desorption isotherms using the Barrett-Joyner-Halenda formula. In the raw bentonite, dry platelets of bentonite which are composed of one octahedral alumina sheet placed between two tetrahedral silica sheets, are most commonly grouped together in face-to-face arrangement, with exchangeable cations and small amounts of water in an interlayer region between each platelet. The intercalation of aryl groups in an interlayer region and the subsequent sulfonation of the intercalated groups (shown in XRD patterns) result in the formation of hydrogen bonding between sulfonic acid functions in the interlayer space, and due to the occupation or even blocking of some solid pores by the modifying agents, the specific surface area and the total pore volume are smaller than that of the H-bentonite. For the AS-BEN catalyst, the average pore diameter was increased due to the reduction of microporous contribution $[13,15,19]$. Nonetheless, some surface areas and porosities were kept in all the meso structures after modification of the pore layers. Hence, when the AS-BEN catalyst was utilized, the reaction takes place in the pores, inner layers, and on the outer surface of the particles.

Table 1. Textural parameters and chemical properties of samples.

\begin{tabular}{ccccc}
\hline Sample & $\begin{array}{c}\mathbf{S}_{\mathbf{B E T}} \\
\left(\mathbf{m}^{\mathbf{2}} \cdot \mathbf{g}^{-\mathbf{1}}\right)\end{array}$ & $\begin{array}{c}\mathbf{V}_{\mathbf{P}} \\
\left(\mathbf{c m}^{\mathbf{3}} \cdot \mathbf{g}^{-\mathbf{1}}\right)\end{array}$ & $\begin{array}{c}\mathbf{D}_{\mathbf{P}}(\text { Average) } \\
(\AA)\end{array}$ & $\begin{array}{c}\text { Acidic Sites } \\
\left(\mathbf{m m o l} \cdot \mathbf{g}^{-\mathbf{1}}\right)\end{array}$ \\
\hline Raw bentonite & 62.1 & 0.178 & 84.4 & - \\
H-bentonite & 76.5 & 0.217 & 83.7 & 1.2 \\
AS-BEN & 5.4 & 0.027 & 123.5 & 1.7 \\
\hline \multicolumn{5}{r}{}
\end{tabular}

The acid capacities of H-BEN and AS-BEN were measured by a neutralization back titration procedure (Table 1). For both samples, $0.1 \mathrm{~g}$ of solid powder was dispersed in $10 \mathrm{~mL}$ of $0.1 \mathrm{M} \mathrm{NaOH}$ solution and slowly shaken at ambient temperature for $24 \mathrm{~h}$. The mixture was finally centrifugedand then the separated alkali solution was titrated against a $0.1 \mathrm{M} \mathrm{HCl}$ standard solution. The concentration of acidic sites (C) was calculated as follow [9]:

$$
\mathrm{C}\left(\frac{\mathrm{mmol}}{\mathrm{g}}\right)=\frac{\text { total mmoles of } \mathrm{NaOH}-\text { remaining mmoles of } \mathrm{NaOH}}{\text { mass of Catalyst }(\mathrm{g})}
$$


In order to investigate the catalytic performance of AS-BEN, we performed the esterification of glycerol with acetic acid as a model reaction. The synthesis of glycerol ester was performed in toluene at optimized conditions of reaction examined in our previous work, acetic acid:glycerol molar ratio of $7,0.074 \mathrm{wt} \%$ of catalyst (based on the total weight of glycerol), and $100{ }^{\circ} \mathrm{C}$. Since water produced as a byproduct could prevent the progress of the reaction, the Dean-Stark trap with toluene in the side arm was used to remove water to significantly improve the glycerol conversion $[4,20]$. The first reaction was performed in toluene as solvent without adding the solid catalyst (blank run) at $0.5 \mathrm{~h}$ and $3 \mathrm{~h}$. As can be seen from Table 2, for both cases conversion of glycerol reached $47 \%$ and $58 \%$, respectively. In the first $0.5 \mathrm{~h}$, the MA selectivity $(85 \%)$ was higher than DA and TA; as the reaction extended, the DA selectivity increased and its maximum selectivity was achieved (36\%) within $3 \mathrm{~h}$. The glycerol conversion and particularly high monoacetin selectivity in the control reaction implied that the synthesis of MA was considerably easier than its acetylation to DA and TA because the Gibb's free energy for synthesis of MA $\left(19.2 \mathrm{~kJ} \cdot \mathrm{mol}^{-1}\right)$ is substantially lower than those of DA $\left(37.0 \mathrm{~kJ} \cdot \mathrm{mol}^{-1}\right)$ and TA $\left(92.5 \mathrm{~kJ} \cdot \mathrm{mol}^{-1}\right)$ [21]. The increase in selectivity for DA and TA within the reaction time is mainly due to the further acetylation of MA.

The above results reflect the contribution of the acetic acid (as weak acidic catalyst), temperature (in endothermic esterification), and toluene as a water removing agent in the progress of glycerol esterification $[4,22]$. It is noted that the conversion and selectivity of glycerol esterification depends on the nature of the catalyst and the reaction parameters. To investigate the catalytic effect of H-bentonite in the present work, the same mole of H-bentonite was utilized. The results showed that H-BEN compared to an AS-BEN catalyst presented an insignificant catalytic effect in esterification of glycerol with acid acetic at an acetic acid/glycerol molar ratio of 7, as show in Table 2. The comparison of H-BEN and AS-BEN catalysts in glycerol esterification reaction performed here implied that the sulfonic acid-functionalized catalyst has a higher catalytic activity for the esterification. The results proposed that configuration of the surface acid moieties may play an important role in the intrinsic kinetics of glycerol esterification, in addition to the number and the strength of the acidic sites [21].

In similar reaction conditions, the AS-BEN catalyst was employed to promote the esterification reaction of glycerol with acetic acid. The typical glycerol conversion and product selectivity in different reaction times are summarized in Table 2. Rapid glycerol conversion in the early stage of the reaction can be explained by a better approachability of active sites of AS-BEN as catalyst which promotes glycerol conversion to MA.

In addition to the increasing conversion, the application of the AS-BEN catalyst strongly affects the selectivity of dominant products. In the first $0.5 \mathrm{~h}$, DA selectivity of $66 \%$ and MA selectivity of $25 \%$ were achieved. The high TA selectivity of $74 \%$ was obtained during $3 \mathrm{~h}$ and within this period, the formation of other oxygenated hydrocarbons as byproducts was not detected at all. The considerable selectivity for TA demonstrated a high activity of the catalyst for formation of TA rather than DA as the product.

The critical factor for the application of any catalyst for industrial purposes is reusability of the catalyst after its consumption. The stability of the catalyst for glycerol conversion and product selectivity was investigated by performing consecutive batch reactions under toluene medium at an acetic acid:glycerol molar ratio of 7, $0.074 \mathrm{wt} \%$ of catalyst (based on the total weight of glycerol), and $100{ }^{\circ} \mathrm{C}$. For using the catalyst in the next run, the solid catalyst was separated from the reaction products by centrifugation, washed in ethanol, and dried to remove deactivating components from the catalyst surface, each cycle was continued for $3 \mathrm{~h}$. 
Table 2. Glycerol esterification reaction with acetic acid.

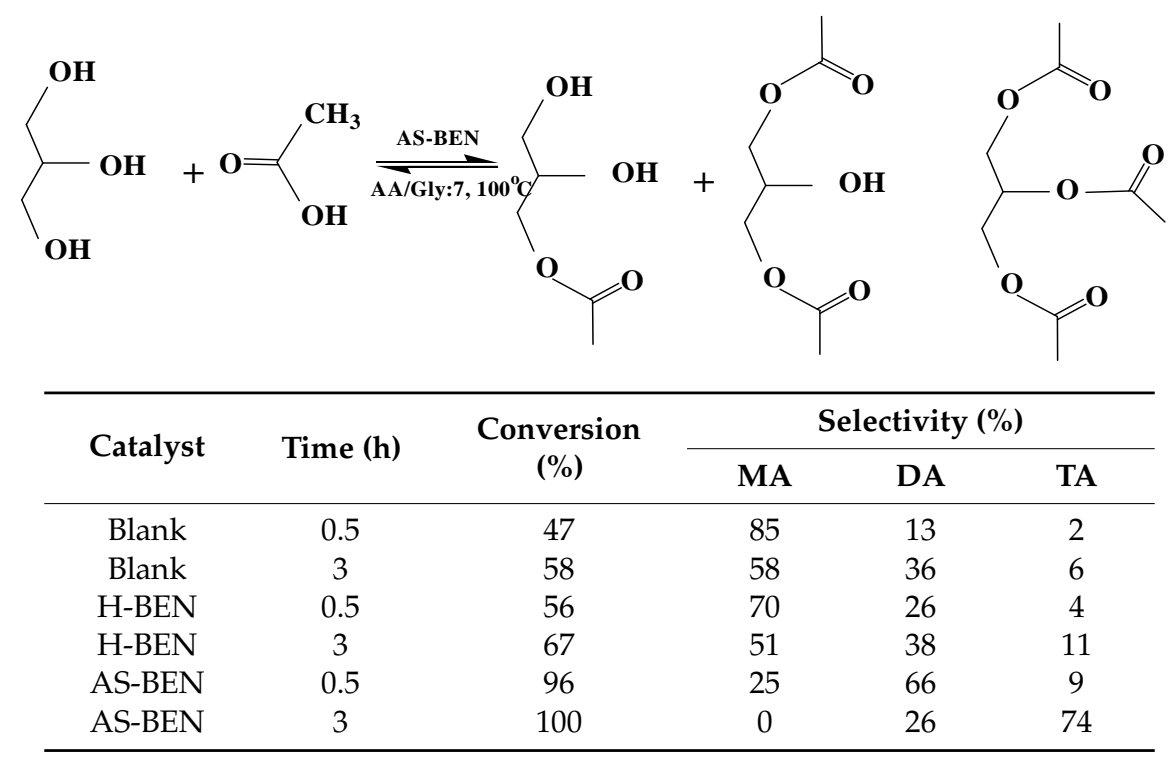

As shown in Figure 5, glycerol conversion and the selectivity to DA and TA do not change considerably, even after reutilization in 5 tests. Moreover, the IR spectrum of the fresh and recycled AS-BEN in Figure 3 demonstrated a resistant catalyst structure after five tests.

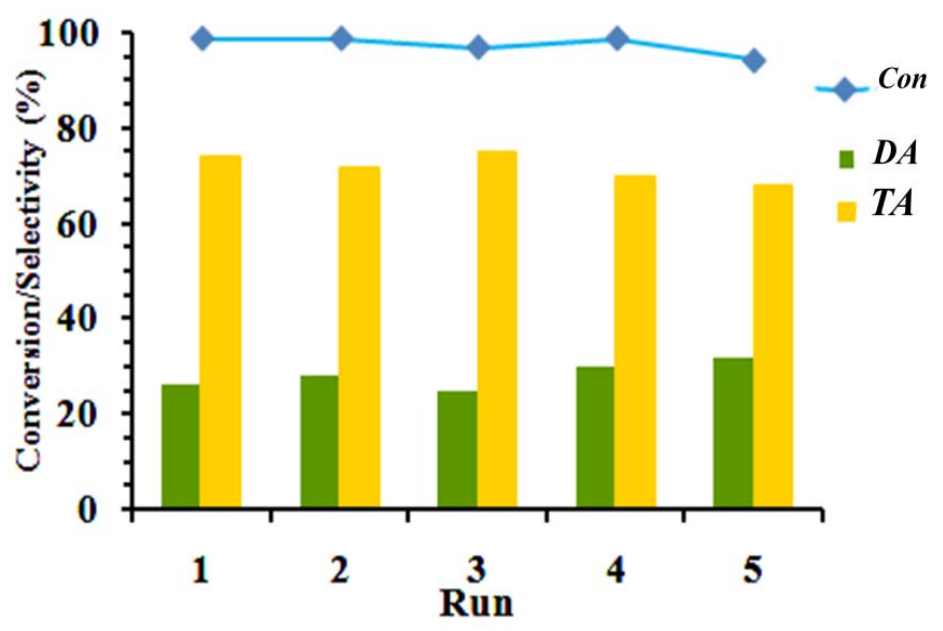

Figure 5. Recycling of AS-BEN at reaction conditions: AA/Gly $=7,3 \mathrm{~h}, 100^{\circ} \mathrm{C}$.

We also compared the catalytic activity of the synthesized catalyst with other solid acidic catalysts, some commercial sulfonic acids such as Amberlyst 15, 35, and 36 with the number of acid sites 4.7, 5.2 , and $5.4 \mathrm{mmol} \cdot \mathrm{g}^{-1}$, respectively, in glycerol esterification with acetic acid. Figure 6 shows the selectivity to acetins produced by each catalyst at the selected reaction time $(3 \mathrm{~h})$. All of the catalysts with the sulfonic acid groups used in the esterification displayed $100 \%$ glycerol conversion. The higher selectivity to the most desirable product (TA) over the AS-BEN was reached at $3 \mathrm{~h}$, compared to Amberlyst 15, 35 and 36.

It is important to note that the Amberlysts 35 and 36 could not be recovered at the end of the reaction and these catalysts are partially disintegrated after $3 \mathrm{~h}$ and fully disintegrated and dissolved in the reaction medium after $8 \mathrm{~h}$. These observations prove that the catalysts are physically/thermally instable in the reaction medium at $100{ }^{\circ} \mathrm{C}$ in the first hours of the reaction. Therefore, the stability of Amberlyst 36 was examined in only toluene that is used as an azeotropic agent in this work, at $100{ }^{\circ} \mathrm{C}$. 
At this condition, the catalyst was completely stable even after $11 \mathrm{~h}$. That is why our previous results in a continuous system with low product residence time over the catalyst [14] are not repeated in a batch system. This work showed that the presence of the catalyst in the reaction medium in a batch system for a long time reduces the stability of Amberlysts 36 and dissolves the catalyst.

The FT-IR spectra of the Amberlyst 36 before and after (disintegrated spent catalyst) the reaction are presented in Figure 7. The FT-IR spectrum of the disintegrated spent Amberlyst 36 after $3 \mathrm{~h}$ of reaction was distinct from the fresh one, demonstrating a partially disintegrated catalyst structure in the reaction medium.

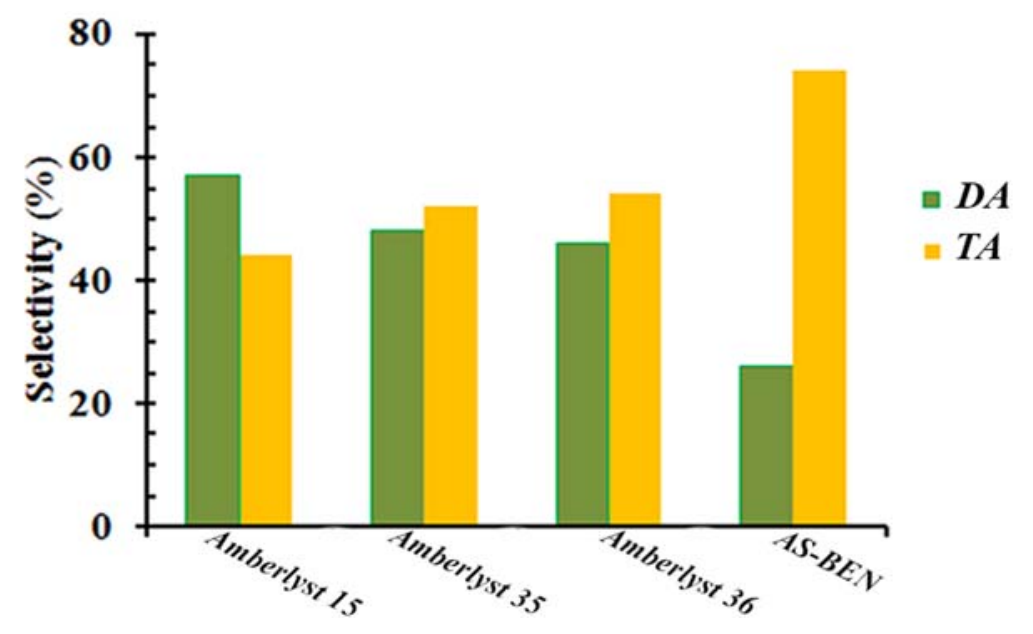

Figure 6. Catalytic behavior of different catalysts at reaction conditions: AA/Gly $=7,3 \mathrm{~h}, 100{ }^{\circ} \mathrm{C}$.

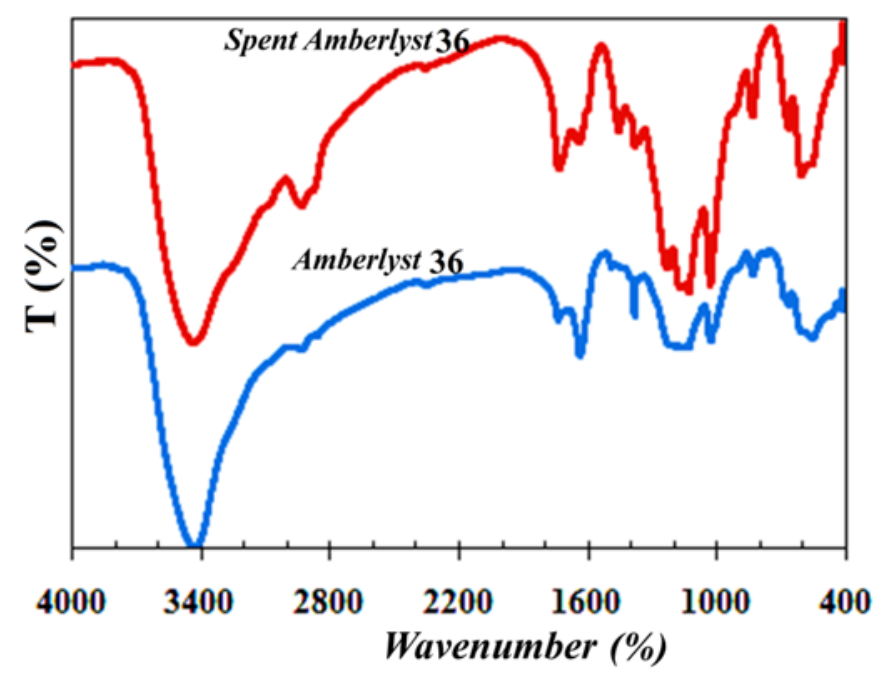

Figure 7. FT-IR spectra of the Amberlyst 36 before and after reaction.

\section{Materials and Methods}

\subsection{Reagents and Analysis}

Acetic acid (purity $>97 \%$ ) was supplied by Fanavaran Petrochemical Co. (Tehran, Iran). Glycerol (purity $>99.9 \%$ ) was supplied by Emery Oleochemicals (Kuala Lumpur, Malaysia). TA (purity $>99 \%$ ) and DA (purity $=50 \%$ ) were supplied byFluka (Seelze, Germany). Absolute ethanol (purity $>99.9 \%$ ) and 2-ethylhexanol (purity $>99 \%$ ) were supplied by Bidestan Co. (Tehran, Iran) and Tat Chemical Co. (Isfahan, Iran), respectively. Wet Amberlyst 36, Amberlyst 35 and Amberlyst 15 were supplied by Sigma-Aldrich (Munich, Germany). MA (purity $>95 \%$ ) was synthesized by the method described 
in previous works [15]. The X-ray diffraction patterns of the catalyst samples were recorded with a X-ray diffractometer, ASENWARE AW-XDM300 (Chaozhou, China), using a $\mathrm{Cu} \mathrm{K} \alpha$ radiation source $(\lambda=1.51418 \AA)$. Infrared spectra were recorded on a JASCO FT-IR-680 plus spectrometer using $\mathrm{KBr}$ transparent discs (Tokyo, Japan). Thermogravimetric analysis (TGA) of the samples were carried out using a Thermoscientific apparatus (Rheometric Scientific, Bayern, Germany). The morphology of the AS-BEN was examined using field emission scanning electron microscopy (FE-SEM), (Mira3-XMU, Freiberg, Germany). The porous structure of the materials was studied by nitrogen adsorption/desorption analysis at $77 \mathrm{~K}$ using a surface area and porosimetric system, model Surfer (Porotec ${ }^{\circledR}$ Co., Hofheim, Germany).

\subsection{Synthesis of ArenesulfonicAcid-Functionalized Bentonite}

The bentonite sample was supplied from Farzin Chemicals Sepahan Co. (Isfahan, Iran). For the preparation of the arenesulfonic acid-functionalized bentonite, the bentonite was acid-activated with $0.1 \mathrm{M} \mathrm{HCl}$ aqueous solution at $90^{\circ} \mathrm{C}$ for $24 \mathrm{~h}$. Then, the solid was separated, washed with water and ethanol until a neutral $\mathrm{pH}$ was achieved, then dried in the oven at $150^{\circ} \mathrm{C}$ for $12 \mathrm{~h}$. For benzyl grafting of acid activated bentonite, $1.5 \mathrm{~g}$ of $\mathrm{H}$-bentonite was added to benzyl alcohol $(7.5 \mathrm{~mL})$ dissolved in dry toluene $(30 \mathrm{~mL})$, and the resulting mixture was refluxed for $24 \mathrm{~h}$ at $110^{\circ} \mathrm{C}$. The obtained solid was washed with toluene and ethanol, centrifuged, and dried. The obtained solid was dispersed in $14 \mathrm{~mL}$ of dry chloroform with strong stirring in a flask placed in an ambient temperature, and $0.8 \mathrm{~mL}$ of chlorosulfonic acid was slowly added in a drop-wise manner for $0.5 \mathrm{~h}$. Then, the product was refluxed at $60{ }^{\circ} \mathrm{C}$ for $4 \mathrm{~h}$. The sample synthesized was filtered and washed with excess water and ethanol and then dried in air at $80^{\circ} \mathrm{C}$ for $12 \mathrm{~h}$.

\subsection{Typical Procedure for the Esterification Reaction}

The reaction of glycerol with acetic acid was performed in a three-neck flask equipped with a magnetic stirrer, thermometer, reflux condenser, and Dean-Stark trap. Before the reaction, all the catalysts were dehydrated at $110{ }^{\circ} \mathrm{C}$ for $3 \mathrm{~h}$ to eliminate the possible remaining water in the catalyst.

The typical catalytic procedure for the synthesis performed in the solution of toluene was as follows: $0.14 \mathrm{~mol}$ (13.58 g) of glycerol, $1 \mathrm{~mol}(60.66 \mathrm{~g})$ of acetic acid, $18.57 \mathrm{~g}$ of toluene (as azeotropic agent) and $1 \mathrm{~g}$ of catalyst ( $0.074 \mathrm{wt} \%$ of catalyst based on the total weight of glycerol) were poured into the reaction vessel and the reaction performed at $100{ }^{\circ} \mathrm{C}$. The optimized reaction parameters such as reaction temperature and acetic acid to glycerol molar ratio are chosen from our previous work [14]. At different time intervals, samples were taken from the reaction mixture and analyzed after separation of the catalysts by centrifugation. The products were identified by gas chromatography/mass spectrometry (GC/MS; model 6890N, Agilent Technologies, Palo Alto, CA, USA).

Then, 2-ethylhexanol (as internal standard) was added to the mixture and the products were analyzed using a gas chromatograph (model SP-3420, Beifen-Ruili Analytical Instrument Co., Ltd., Beijing, China) equipped with a flame ionization detector and a capillary column (SUPELCO, Equity ${ }^{\mathrm{TM}} 1701$, Darmstadt, Germany). The column temperature was set at an initial value of $80^{\circ} \mathrm{C}$, ramped to $150{ }^{\circ} \mathrm{C}$ at a rate of $30^{\circ} \mathrm{C} \cdot \mathrm{min}^{-1}$, ramped from $150{ }^{\circ} \mathrm{C}$ to $240{ }^{\circ} \mathrm{C}$ at a rate of $10{ }^{\circ} \mathrm{C} \cdot \mathrm{min}^{-1}$, and held at $240{ }^{\circ} \mathrm{C}$ for $2 \mathrm{~min}$. The GC injection port and the detector temperature were set at $290^{\circ} \mathrm{C}$ and $300{ }^{\circ} \mathrm{C}$, respectively. The chromatographic calibration curve for each individual component was used for quantitative determination of the sample components. The relative standard deviation for replicate gas chromatography-flame ionization detector (GC-FID) analyses was $<2 \%$.

Glycerol conversion (\%), product yield (\%), and each product selectivity (\%) were calculated as follows [23]:

$$
\begin{gathered}
\text { Glycerol conversion/yield }(\%)=\frac{\text { moles of glycerol reacted }}{\text { moles of glycerol taken }} \times 100 \\
\text { Product selectivity }(\%)=\frac{\text { moles of product obtained }}{\text { total moles of products }} \times 100
\end{gathered}
$$




\section{Conclusions}

The esterification of glycerol with acetic acid was performed over AS-BEN as a stable and strong acidic catalyst in the reaction medium at atmospheric pressure, $100{ }^{\circ} \mathrm{C}$, and acetic acid/glycerol mole ratio of 7. A Dean-Stark trap containing toluene was added to the flask to separate water from the reaction mixture. AS-BEN was prepared by grafting arenesulfonic groups into the bulk bentonite as a support material. The $96 \%$ glycerol conversion and selectivity of $25 \%, 66 \%$, and $9 \%$ toward MA, DA, and TA, respectively, was achieved after $0.5 \mathrm{~h}$. The high TA selectivity of $74 \%$ was reached after $3 \mathrm{~h}$ of reaction. The lifetime and stability of the catalyst was investigated by conducting reusability tests. Finally, the present catalyst was the best one among all other catalysts tested due to its high thermal (at around $250^{\circ} \mathrm{C}$ ) and physical stability, long life time (over $15 \mathrm{~h}$ ), and good catalytic performance.

Acknowledgments: This work was partially supported by Isfahan University of Technology.

Author Contributions: Hassan S. Ghaziaskar and Maryam Tangestanifard designed the experiments of the project. Maryam Tangestanifard carried out the synthetic works as part of her PhD project. Hassan S. Ghaziaskar supervised the whole studies reported in the manuscript. Hassan S. Ghaziaskar and Maryam Tangestanifard wrote the manuscript.

Conflicts of Interest: The authors declare no conflict of interest.

\section{References}

1. Trejda, M.; Stawicka, K.; Dubinska, A.; Ziolek, M. Development of niobium containing acidic catalysts for glycerol esterification. Catal. Today 2012, 187, 129-134. [CrossRef]

2. Zhou, C.H.; Zhao, H.; Tong, D.S.; Wu, L.M.; Yu, W.H. Recent advances in catalytic conversion of glycerol. Catal. Rev. 2013, 55, 369-453. [CrossRef]

3. Nanda, M.R.; Zhang, Y.; Yuan, Z.; Qin, W.; Ghaziaskar, H.S.; Xu, C. Catalytic conversion of glycerol for sustainable production of solketal as a fuel additive: A review. Renew. Sustain. Energy Rev. 2016, 56, 1022-1031. [CrossRef]

4. Roze, M.; Kampars, V.; Teivena, K.; Kampare, R.; Liepins, E. Catalytic etherification of glycerol with alcohols. Mater. Sci. Appl. Chem. 2013, 28, 67-72. [CrossRef]

5. Rane, S.A.; Pudi, S.M.; Biswas, P. Esterification of glycerol with acetic acid over highly active and stable alumina-based catalysts: A reaction kinetics study. Chem. Biochem. Eng. Q. 2016, 30, 33-45. [CrossRef]

6. Melero, J.A.; Grieken, R.V.; Morales, G.; Paniagua, M. Acidic mesoporous silica for the acetylation of glycerol: Synthesis of bioadditives to petrol. Energy Fuels 2007, 21, 1782-1791. [CrossRef]

7. Mallesham, B.; Sudarsanam, P.; Raju, G.; Reddy, B.M. Design of highly efficient Mo and W-promoted $\mathrm{SnO}_{2}$ solid acids for heterogeneous catalysis: Acetalization of bio-glycerol. Green Chem. 2013, 15, 478-489. [CrossRef]

8. Liu, X.; Ma, H.; Wu, V.; Wang, C.; Yang, M.; Yan, P.; Welz-Biermann, U. Esterification of glycerol with acetic acid using double $\mathrm{SO}_{3} \mathrm{H}$-functionalized ionic liquids as recoverable catalysts. Green Chem. 2011, 13, 697-701. [CrossRef]

9. Khayoona, M.S.; Triwahyono, S.; Hameed, B.H.; Jalil, A.A. Improved production of fuel oxygenates via glycerol acetylation with acetic acid. Chem. Eng. J. 2014, 243, 473-484. [CrossRef]

10. De Oliveira, R.N.; Xavier, A.D.L.; Guimaraes, B.M.; Melo, V.N.E.; Valenca, W.O.; Do Nascimento, W.S.; Da Costa, P.L.F.; Camara, C.A. Combining clays and ultrasound irradiation for an $O$-acetylation reaction of N-glucopyranosyl and other molecules. J. Chil. Chem. Soc. 2014, 59, 2610-2614. [CrossRef]

11. Venkatesha, N.J.; Bhat, Y.S.; Jai Prakash, B.S. Volume accessibility of acid sites in modified montmorillonite and triacetin selectivity in acetylation of glycerol. RSC Adv. 2016, 6, 45819-45828. [CrossRef]

12. Jagadeeswaraiah, K.; Balaraju, M.; Prasad, P.S.S.; Lingaiah, N. Selective esterification of glycerol to bioadditives over heteropolytungstate supported on Cs-containing zirconia catalysts. Appl. Catal. A-Gen. 2010, 386, 166-170. [CrossRef]

13. Moraes, D.S.; Angélica, R.S.; Costa, C.E.F.; Rocha Filho, G.N.; Zamian, J.R. Bentonite functionalized with propyl sulfonic acid groups used as catalyst in esterification reactions. Appl. Clay Sci. 2011, 51, $209-213$. [CrossRef] 
14. Rastegari, H.; Ghaziaskar, H.S.; Yalpani, M. Valorization of biodiesel derived glycerol to acetins by continuous esterification in acetic acid. Ind. Eng. Chem. Res. 2015, 54, 3279-3284. [CrossRef]

15. Guimarães, A.D.M.F.; Ciminelli, V.S.T.; Vasconcelos, W.L. Smectite organofunctionalized with thiol groups for adsorption of heavy metal ions. Appl. Clay Sci. 2009, 42, 410-414.

16. Sasikala, S.; Meenakshi, S.; Bhat, S.D.; Sahu, A.K. Functionalized bentonite clays PEEK based composite membranes for direct methanol fuel cells. Electrochim. Acta 2014, 135, 232-241. [CrossRef]

17. Nakamoto, K. Infrared and Raman Spectra of Inorganic and Coordination Compounds, Part II: Application in Coordination, Organometallic and Bioinorganic Chemistry, 5th ed.; Wiley-Interscience: New York, NY, USA, 1997; pp. 81-82.

18. Leng, Y.; Zhao, J.; Jiang, P.; Lu, D. POSS-derived solid acid catalysts with excellent hydrophobicity for highly efficient transformations of glycerol. Catal. Sci. Technol. 2016, 6, 875-881. [CrossRef]

19. Mercier, L.; Pinnavaia, T.J. Heavy metal ion adsorbents formed by the grafting of a thiol functionality to mesoporous silica molecular sieves: Factors affecting $\mathrm{Hg}(\mathrm{II})$ Uptake. Environ. Sci. Technol. 1998, 32, 2749-2754. [CrossRef]

20. Sudarsanam, P.; Mallesham, B.; Reddy, P.S.; Reddy, B.M. Highly promising sulfate ion promoted $\mathrm{M}-\mathrm{ZrO}_{2}$ $\left(\mathrm{M}=\mathrm{Al}_{2} \mathrm{O}_{3}\right.$ and $\left.\mathrm{CeO}_{2}\right)$ heterogeneous solid acids for biodiesel derived glycerol esterification. J. Chem. Sci. Technol. 2013, 2, 161-168.

21. Kim, I.; Kim, J.; Lee, D. A comparative study on catalytic properties of solid acid catalysts for glycerol acetylation at low temperatures. Appl. Catal. B-Environ. 2014, 148-149, 295-303. [CrossRef]

22. Bosco, S.M.D.; Goncalves, M.; Figueiredo, F.C.A.; Galhardo, T.; Carvalho, W.A. Sulfated pillared clay as catalyst in glycerol esterification with caprylic acid. Waste Biomass Valor. 2016, 7, 1279-1288. [CrossRef]

23. Rastegari, H.; Ghaziaskar, H.S. From glycerol as the by-product of biodiesel production to value-added monoacetin by continuous and selective esterification in acetic acid. J. Ind. Eng. Chem. 2015, 21, 856-861. [CrossRef]

(C) 2017 by the authors. Licensee MDPI, Basel, Switzerland. This article is an open access article distributed under the terms and conditions of the Creative Commons Attribution (CC BY) license (http:/ / creativecommons.org/licenses/by/4.0/). 